\title{
Impact of a Training Intervention for Usein Emergency Situations on Knowledge and Skills Acquisition by Undergraduate Students
}

\author{
Silmara Meneguin ${ }^{1}$, Camila Fernandes Pollo ${ }^{2}$, Miriane Garuzi ${ }^{3}$, Helio Amante $\mathrm{Miot}^{4}$ \\ ${ }^{1}$ Nurse, Assistant Professor, São Paulo State University “Julio de Mesquita Filho”, Botucatu Campus, Faculty of Medicine, \\ São Paulo, Brazil. \\ ${ }^{2}$ Nurse, Student of the Doctor Degree Program. São Paulo State University “Julio de Mesquita Filho", Botucatu Campus, \\ Faculty of Medicine, São Paulo, Brazil. \\ ${ }^{3}$ Doctor, Student of the Master Degree. São Paulo State University “Julio de Mesquita Filho”, Botucatu Campus, Faculty \\ of Medicine, São Paulo, Brazil. \\ ${ }^{4}$ Doctor, Assistant Professor, São Paulo State University "Julio de Mesquita Filho", Botucatu Campus, Faculty of \\ Medicine, São Paulo, Brazil.
}

Correspondence: Silmara Meneguin, Botucatu Medical School- Nursing Department, 18618-687 - Botucatu - SP, Brazil.

Funding Sources: São Paulo Research Foundation (Fapesp)-Process number 2012/00288-1

Conflicts of Interest: None.

Received: Nov. 18, 2019

Accepted: Feb. 26, $2020 \quad$ Online Published: Mar. 4, 2020

doi:10.11114/jets.v8i5.4616

URL: https://doi.org/10.11114/jets.v8i5.4616

\begin{abstract}
The aim of this study was to evaluate the impact of an intervention aimed at the enhancing of undergraduate students in emergency situations and to identify the factors related to the acquisition of participants' knowledge and skills. This was an intervention study using a convenience sample of 424 students from different campuses of a public university in the interior of São Paulo State, Brazil. Theoretical learning was assessed using pre-test and post-test multiple-choice questions, and skills in basic life support were assessed via simulation using a mannequin, immediate feedback devices and a checklist. The mean knowledge score attained was $15.1(\mathrm{SD} \pm 3.50)$ on the pre-test and20.9 $(\mathrm{SD} \pm 3.20)$ on the post-test $(\mathrm{p}<$ 0.001). Regarding basic cardiopulmonary resuscitation skills, the mean scores before and after the training were $36.3(\mathrm{SD}= \pm 5.3)$ and178 $(\mathrm{SD} \pm 28.3)$ respectively $(\mathrm{p}<0.001)$. Age was associated with an increase in knowledge and skills' score when comparing before and after training scores $(\mathrm{p}=0.0000)$. The practical basic life support training intervention received an assessment of 75.4\% from students of all areas. The training intervention contributed to improvement in both knowledge of care in emergency situations and basic life support skills. Age was the only factor that independently influenced the development of learning and psychomotor skills.
\end{abstract}

Keywords: teaching, learning, cardiopulmonary resuscitation, emergencies

\section{Introduction}

Emergency situations unexpectedly arise in people's lives requiring the initiation of quick, objective and effective actions. Suboptimal recognition of symptoms and incorrect evaluation of emergency situations encountered occurs in approximately $83.7 \%$ of cases in the extra-hospital environment (Tannvik et al., 2012).

Training and instructing the lay population on the appropriate care to provide in emergency situations enhances the chances of survival of victims and reduces the impact of resulting sequelae (Viereck et al., 2017). This is because it limits the chances of a rescuer's paralysis when confronted with the unexpected (Gebreegziabher Gebremedhn et al., 2017)(Viereck et al., 2017).

Care in emergencies situations necessitates that the victim ought to receive immediate attention (Bakke et al., 2016)(De Buck et al., 2015). Such situations or conditions that require immediate intervention to avoid serious adverse events are referred to as emergencies (DEcs, MeSH). 
The immediate care provided to a victim of an accident or sudden illness, is executed by a person trained to maintain vital signs and prevent worsening of existing injuries until the arrival of qualified care is, referred to as a first-aid measure (Van de Velde et al., 2007).

Listed among first-aid measures is basic life support (BLS) that includes cardiopulmonary resuscitation (CPR). CPR can be initiated outside hospital by trained lay persons, thus increasing the chances of survival and minimizing the sequelae of a cardiac arrest in a victim (Sladjana, 2011).This care comprises the immediate recognition of a problem, activation of an emergency response system, and the provision of early CPR and rapid defibrillation (Berg et al., 2010).

Cardiac arrests that occur outside hospitals represent not only an important global health problem, but also one of the main causes of mortality in developed countries (Mawani et al., 2016)(Ro et al., 2013). The prevalence of cardiorespiratory arrest may also be affected by factors such as systemic diseases, especially cardiovascular diseases (Smereka et al., 2019).

In the United States and Europe, the total number of annual cardiac arrest rates amounts to 420,000 and 275,000 respectively (Atwood et al., 2005)( Go et al., 2014).

A systematic review of 60 research studies showed great variation in the incidence and outcomes of cardiac arrest in different communities (Viereck et al., 2017). The global incidence of cardiac arrests was estimated to be55 per 100,000 individuals/year with a survival rate of between 2 and 11\% (Berdowski et al., 2010). The lack of uniformity in care is probably one of the reasons for this disparity in survival (Berg et al., 2010).

In Brazil, there are no official data, nor studies on the magnitude of this event. Nevertheless, about 200,000 cases of cardiac arrests occur each year, half of which occur in hospital, and the other half outside hospital settings, e.g. at home, in shopping malls, airports, stadiums, among others (Gonzalez et al., 2013).

Therefore, immediate intervention for persons with cardiac arrest by instituting CPR prior to the arrival of specialized emergency care teams, is crucial to enhance the chances of survival of persons with cardiac arrest (Kleinman et al., 2015).

In a recent study in Hong Kong, of 5,154 cases of out-of-hospital cardiac arrest cases, the majority occurred at home and $8.7 \%$ were due to fibrillation or ventricular tachycardia ( Shenzhen, 2017).

This means that out-of-hospital victims of cardiac arrest have little chance of successful ressuscitation without basic immediate CPR maneuvers by the closest person who usually is a lay person (Ko et al., 2018).

With every minute of delay in CPR, the victim of cardiac arrest's chances of survival decrease by 7 to $10 \%$. However, if CPR is initiated in time with the use of the DEA, it can help save lives. In addition, the timely institution of CPR in cases of cardiac arrest has led to an improvement survival results by approximately 50\% (Stiell et al., 2003).

The fact that CPR training is not provided in undergraduate programs implies that students may not be prepared to act in emergency situations, for instance at home. This was what motivated us to undertake this research.

We hypothesized that theoretical-practical training for care in emergency situations would contribute to enhanced learning and acquisition of psychomotor skills in the basic life support technique among students undergraduate programs.

The aim of this study was to evaluate the impact of an intervention aimed at the enhancing of undergraduate students in emergency situations and to identify the factors related to the acquisition of participants' knowledge and skills.

\section{Methods}

This was a quantitative intervention study with a before and after design, without a control group, carried out at the campuses of a public university in the interior of São Paulo, between March 2013 and October 2014.

To recruit participants, course coordinators were contacted to authorize the conduct of research and inclusion of CPR training in the training curriculum. Training sessions occurred on two consecutive days. Undergraduate students were considered eligible for participation if they were regularly enrolled and consented to participate. Participants who did not participate in all the stages of the training were excluded from the final analyses. In a convenience sample of 484 students who accepted to participate, 60 were excluded from the final analyses.

The data was collected at two time points: at M1- pre-intervention and M2- post-intervention time points. The following instruments were used: a) a questionnaire comprised of 30 objective multiple-choice questions regarding emergency care with each question being worth one point. This instrument, prepared by reviewing and prior analysis of the literature, was focused on the responder's recognition of an emergency situation, evaluation of the accident site, victim protection and the following emergency situations: hemorrhage, asphyxiation, shock, injuries, seizures, burns, drowning, fractures, accidents with venomous animals and basic life support; b) a 20-item checklist based on basic life support skills (Berg, 2010), with a maximum score of 187 points; c) a mobile electronic device providing immediate feedback following 
performance of CPR chest compressions (i.e. the rhythm, depth, frequency and release of the thorax at each compression) (a.ka. adult Resusci Anne simulator with Skill Guide software).

Both the questionnaire and the checklist were pre-tested by six specialists ( 2 physicians and 4 nurses) with experience in teaching, research, emergency care and simulation laboratory.

The simulation of out-of-hospital basic life support care in adults took place individually at each training site, that is, on different university campuses. One researcher assessed the simulations with the help of a printed checklist and electronic feedback devices.

The theoretical framework employed was the Significant Learning Theory, which assumes that new knowledge is only acquired from material that is interesting (meaningful) to the student and is anchored in the student's previous knowledge. The central point of reflection on this theory is that, of all the factors that influence learning, of the utmost importance is what the student already knows, an aspect considered a starting point for successful learning (Ausubel et al., 1991).

Thus, learning implies attributing meaning to new knowledge, using personal components already present in the cognition of each subject (Moreira, 2014)(Moreira, 2012).

For there to be meaningful learning, two conditions are necessary: firstly, the student must be willing to learn. If he only wants to memorize the content, the learning will be mechanical, without any incorporation of new knowledge into the knowledge that he already possesses. Secondly, the content presented must be logical and psychologically significant to the learner. The logical meaning is the evident and coherent meaning, whereas the psychological meaning is the experience that each individual brings from his point of view, i.e. his previous experiences (Pelizzari et al., 2002).

Within this study, a problem situation related to an emergency situation was used as a teaching strategy that required students to undertake a personal search to solve the problem, thereby contributing to meaningful learning.

Initially, all variables were analyzed descriptively. Qualitative variables were described as percentages or mean hit fractions. Quantitative variables were described as means and standard deviations or medians and quartiles (p25-p75) based on the distribution of data as assessed by Shapiro-Wilk test.

Linear regression models were adjusted to describe relationships between the scores obtained and age, sex, background training and experience in emergency situations. The correlation between the pre and post-training scores was evaluated using Spearman's coefficient (rho).

Differences were considered significant if $\mathrm{p}<0.05$. The analyses were developed in IBM SPSS, version 22 . Significance was set at $5 \%$.

\section{Results}

Based on the inclusion criteria, 424 students participated in the training, most of whom were female 241(56.8\%), studied exact sciences 239 (56.4\%) and had an average age of 20.6 years. About $22 \%$ of all students had received background training courses at state-owned technical schools (ETECs), drivers training centers and junior firefighter programs without any training in basic life support training, and $6.1 \%$ indicated having had an experience in an emergency situation in the past. Only the mean age and sex distribution of participants differed significantly between students from the exact sciences and the basis sciences. (Table 1).

Table 1. Characteristics of study participants according to knowledge areas.

\begin{tabular}{|c|c|c|c|c|c|c|c|}
\hline \multirow{3}{*}{ Variable } & \multicolumn{4}{|c|}{ Knowledge areas } & & & \multirow{3}{*}{$\mathbf{p}$} \\
\hline & \multicolumn{2}{|c|}{$\begin{array}{c}\text { Biomedical Sciences } \\
\qquad \mathrm{N}=185\end{array}$} & \multicolumn{2}{|c|}{$\begin{array}{c}\text { Exact Sciences } \\
\quad \mathrm{N}=\mathbf{2 3 9}\end{array}$} & \multicolumn{2}{|c|}{ Total } & \\
\hline & $\mathbf{N}$ & $\%$ & $\mathbf{N}$ & $\%$ & $\mathbf{N}$ & $\%$ & \\
\hline Male Sex & 30 & 16.2 & 153 & 64 & 183 & 43.2 & 0.000 \\
\hline Received background training & 45 & 24.3 & 49 & 20.5 & 94 & 22.2 & 0.347 \\
\hline $\begin{array}{l}\text { Prior experience in } \\
\text { Emergency Situations }\end{array}$ & 7 & 1.6 & 19 & 4.4 & 26 & 6.1 & 0.1000 \\
\hline Mean Age $( \pm$ SD $)$ & 19.83 & $( \pm 2.75)$ & 21.19 & $( \pm 4.40)$ & 20.60 & $( \pm 43.83)$ & 0.000 \\
\hline
\end{tabular}

SD: Standard Deviation

In Table 2, the pre- and post-training scores about knowledge and skills are presented. The difference between the scores demonstrates a knowledge increase of almost $40 \%$ after the training when compared to before the training. A significant difference between the pre- and post-training scores on skills with an average increase of 141 points was also observed $(\mathrm{p}<0.001)$. 
Table 2. Description of knowledge and skills scores obtained before and after training

\begin{tabular}{|c|c|c|c|c|}
\hline \multicolumn{5}{|c|}{ Knowledge } \\
\hline & $\begin{array}{c}\text { Score } \\
\text { M1 }\end{array}$ & $\begin{array}{c}\text { Score } \\
\text { M2 }\end{array}$ & Difference & $\mathbf{p}$ \\
\hline Mean (SD) & $15.1 \pm 3.50$ & $20.9 \pm 3.20$ & $5.8 \pm 3.98$ & \\
\hline Median (IQR) & $15(13-17)$ & $21(19-23)$ & $6(3-8)$ & $<0.001$ \\
\hline Range & $6-27$ & $10-27$ & $10-19$ & \\
\hline \multicolumn{5}{|c|}{ Skills } \\
\hline Mean (SD) & $36.3 \pm 25.3$ & $178 \pm 28.3$ & $141 \pm 37.3$ & \\
\hline Median & 30 & 187 & 148 & \\
\hline (IQR) & $(19-49)$ & $(148-187)$ & $(128-167)$ & $<0.001$ \\
\hline Range & $0-158$ & $0-187$ & $49-187$ & \\
\hline
\end{tabular}

M1 - Moment 1(before the training); M2 - Moment 2 (after the training); SD: Standard Deviation; IQR: interquartile range

Table 3 shows linear regression models adjusted to describe the relationship between scores obtained regarding the theoretical knowledge of emergency situations and CPR maneuvers and age, sex, having previous training and having worked in an emergency situation in the pre and post test.

It was noted that the skills' score before training increased by 1.79 points for each year increase in age and by 6.6 for male participants. After the training, only the relationship between age and test scores remained significant with an increase of 8.21 points for each year increase in age.

Before training, there was a significant relationship between age and previous training, with test scores increasing by 0.48 points for each year increase in age and by 1.10 points for those who have they had taken the course previously. After the training, only the age had a significant relationship with the theoretical knowledge score with the magnitude of the effect practically identical to the pre-training magnitude.

Table 3. Linear regression model illustrating relationship between participant characteristics and changes in pre and post- test knowledge and skills' scores

\begin{tabular}{|c|c|c|c|c|c|c|c|}
\hline Model & Variable & B & ep & $\mathbf{T}$ & $\mathbf{P}$ & \multicolumn{2}{|c|}{ IC95\% } \\
\hline \multirow{4}{*}{$\begin{array}{l}\text { Skills Score Pre- } \\
\text { Training }\end{array}$} & Age (years) & 1.79 & 0.09 & 19.13 & 0.000 & 1.61 & 1.97 \\
\hline & Male sex & -6.60 & 2.62 & -2.52 & 0.012 & -11.74 & -1.46 \\
\hline & Background training & 3.75 & 2.84 & 1.32 & 0.186 & -1.82 & 9.33 \\
\hline & Experience in emergency & -1.90 & 5.29 & -0.36 & 0.720 & -12.30 & 8.51 \\
\hline \multirow{4}{*}{$\begin{array}{l}\text { Skills Score Post- } \\
\text { Training }\end{array}$} & Age (years) & 8.21 & 0.16 & 52.15 & 0.000 & 7.90 & 8.52 \\
\hline & Male sex & 3.67 & 4.40 & 0.83 & 0.405 & -4.98 & 12.33 \\
\hline & Background training & 5.16 & 4.77 & 1.08 & 0.280 & -4.22 & 14.54 \\
\hline & Experience in emergency & 1.79 & 0.09 & 19.13 & 0.000 & 1.61 & 1.97 \\
\hline \multirow{4}{*}{$\begin{array}{c}\text { Knowledge about } \\
\text { Emergency Score Pre- } \\
\text { Training }\end{array}$} & Age (years) & 0.48 & 0.01 & 47.41 & 0.000 & 0.46 & 0.50 \\
\hline & Male sex & -0.33 & 0.28 & -1.16 & 0.246 & -0.89 & 0.23 \\
\hline & Background training & 1.10 & 0.31 & 3.58 & 0.000 & 0.50 & 1.71 \\
\hline & Experience in emergency & -0.55 & 0.57 & -0.95 & 0.343 & -1.67 & 0.58 \\
\hline \multirow{4}{*}{$\begin{array}{l}\text { Knowledge about } \\
\text { Emergency Score Post- } \\
\text { Training }\end{array}$} & Age (years) & 0.59 & 0.01 & 49.01 & 0.000 & 0.57 & 0.61 \\
\hline & Male sex & -0.18 & 0.34 & -0.54 & 0.592 & -0.84 & 0.48 \\
\hline & Background training & 0.66 & 0.37 & 1.81 & 0.071 & -0.06 & 1.38 \\
\hline & Experience in emergency & 0.20 & 0.68 & 0.29 & 0.769 & -1.14 & 1.54 \\
\hline
\end{tabular}

In Table 4, the participants' perception of the physical and pedagogical aspects and their self-assessment of the training in emergency situations are summarized.

Most students rated the organization, dissemination and timing of the course as excellent. Half of the participants (52.3\%) considered the facilities either good or very good. This could be because the training took place in locu and not in simulation labs as is the ideal condition. 
The students evaluated the materials presented and the slides used to present the theoretical content as excellent 300 (70.7\%).

The practical basic life support activity received one of the best assessments $(\mathrm{n}=320 ; 75.4 \%)$ based on assessments from students of both disciplines i.e. material and exact sciences. The same was true for the theoretical content addressed by the training course $(\mathrm{n}=308 ; 72.6 \%)$. Items involving self-assessment, such as utilization and learning opportunity, were also rated as excellent by the students.

Table 4. Participants' perception of physical and pedagogical aspects and self-assessment of the training

\begin{tabular}{|c|c|c|c|c|c|c|c|c|c|c|c|c|}
\hline \multirow{3}{*}{$\begin{array}{l}\text { Aspects } \\
\text { assessed }\end{array}$} & \multicolumn{12}{|c|}{ Concepts } \\
\hline & \multicolumn{2}{|c|}{ Very bad } & \multicolumn{2}{|c|}{ Bad } & \multicolumn{2}{|c|}{ Regular } & \multicolumn{2}{|c|}{ Good } & \multicolumn{2}{|c|}{ Very good } & \multicolumn{2}{|c|}{ Excellent } \\
\hline & $\mathrm{N}$ & $\%$ & $\mathrm{~N}$ & $\%$ & $\mathrm{~N}$ & $\%$ & $\mathrm{~N}$ & $\%$ & $\mathrm{~N}$ & $\%$ & $\mathrm{~N}$ & $\%$ \\
\hline Organization & 0 & 0.0 & 0 & 0.0 & 5 & 1.1 & 53 & 12.5 & 154 & 36.3 & 212 & 50.0 \\
\hline Dissemination & 4 & 0.9 & 8 & 1.8 & 3 & 0.7 & 144 & 33.9 & 85 & 20.0 & 180 & 42.4 \\
\hline Time & 0 & 0.0 & 0 & 0.0 & 9 & 2.1 & 107 & 25.2 & 110 & 25.9 & 188 & 44.3 \\
\hline Facilities & 2 & 0.4 & 0 & 0.0 & 13 & 3.0 & 100 & 23.5 & 122 & 28.7 & 187 & 44.1 \\
\hline Material & 0 & 0.0 & 0 & 0.0 & 3 & 0.7 & 27 & 6.36 & 94 & 22.1 & 300 & 70.7 \\
\hline Slides & 0 & 0.0 & 0 & 0.0 & 0 & 0.0 & 47 & 11.0 & 111 & 26.1 & 266 & 62.7 \\
\hline $\begin{array}{l}\text { Practical } \\
\text { activity }\end{array}$ & 0 & 0.0 & 0 & 0.0 & 0 & 0.0 & 23 & 5.4 & 81 & 19.1 & 320 & 75.4 \\
\hline $\begin{array}{l}\text { Content of } \\
\text { themes } \\
\text { addressed }\end{array}$ & 0 & 0.0 & 0 & 0.0 & 1 & 0.2 & 11 & 2.5 & 104 & 24.5 & 308 & 72.6 \\
\hline Utilization & 0 & 0.0 & 0 & 0.0 & 4 & 0.9 & 27 & 6.3 & 114 & 26.8 & 279 & 65.8 \\
\hline $\begin{array}{l}\text { Learning } \\
\text { opportunity }\end{array}$ & 0 & 0.0 & 0 & 0.0 & 0 & 0.0 & 11 & 2.5 & 66 & 15.5 & 347 & 58.2 \\
\hline
\end{tabular}

In Table 5, comments documented in the participants' course assessments sheets are summarized. Almost half of the participants (45.2\%) were grateful for the opportunity to participate in the training on emergency situations and $29 \%$ recommended that it ought be mandatory for all professionals and students at the university. For the vast majority (48.1\%), the course was perceived as easy to understand and important in the performance of certain procedures.

Table 5. Comments documented in the participants' course assessment sheets

\begin{tabular}{lrr}
\hline \multicolumn{1}{c}{ Comments } & N & \% \\
\hline The dissemination should be better & 35 & 8.2 \\
The practice should only involve the teacher and the student & 10 & 2.3 \\
Have more time to practice & 58 & 13.6 \\
Practice other topics beyond CPR & 43 & 10.1 \\
Add videos on other different practical situations, such as help in convulsion situations & 28 & 6.6 \\
Grateful for the opportunity & 192 & 45.2 \\
Importance of this course for students in fishing engineering & 45 & 10.6 \\
Offer more advanced emergency help courses & 5 & 1.1 \\
The course should be obligatory for all professionals and students on the campus & 123 & 29.0 \\
It was simple, easy and important to understand why we execute certain procedures & 204 & 48.1 \\
\hline
\end{tabular}

\section{Discussion}

These study results indicate a significant increase in the number of correct answers to the theoretical questions and in the checklist of psychomotor skills after the training.

The application of the questionnaire, before the educational intervention, was important to identify basic notions acquired by previous knowledge. In this way, it was possible to identify known basic concepts about the care of emergency situations, so that new knowledge was anchored and modified therefore expanding the cognitive structure by incorporating new ideas (Sousa et al., 2015)(Mendoza \& Peniche, 2012). 
Furthermore, the use of a problem situation as a teaching strategy for educational purposes allowed a conceptual approach, as well as a detailed and objective analysis of a real situation to be used as a trigger for learning (Prado et al., 2011).

The use of active methodologies stimulated the teaching-learning process in a critical-reflective way about the problem presented, making the student an active participant in the process of building their own knowledge (Sobral \& Campos, 2012).

Regarding sociodemographic data, most participants were young, female and had little previous experience in emergency response situations. These data corroborate results from a study in an Ethiopian teaching hospital with 461 health professionals, in which their skills and attitudes towards CPR procedures were assessed. In the Ethiopian survey, 66.4 were women, with a mean age of 19.3 years and living in urban areas (52.9\%) (Gebreegziabher Gebremedhn et al., 2017).

As regards background participation in emergency courses, $30 \%$ of the respondents reported this experience, but this experience did not include basic life support and training practice. Unfortunately, there are no public initiatives in our country to train laypeople in out-of-hospital emergency cardiac arrest care. However, this is not peculiar to our country. A study conducted in USA showed that of 521 lay persons who completed BLS training, nearly half (47\%) had never received CPR training (Leary et al., 2017).

A recent study conducted in Portugal on 1697 participants working in public and private institutions, only $17.8 \%$ had had background training in BLS, mostly provided by the Portuguese Red Cross (23.5\%). In this survey, $14.6 \%$ of the respondents reported the need to provide BLS training to lay persons (Dixe \& Gomes, 2015).

In the knowledge assessment, the students' average score after the training increased by 5.81 points illustrating a knowledge gain following the training. Empowering laypeople to provide preliminary care in emergency situations and BLS is critical to save lives and prevent unfavorable sequelae. Nevertheless, many studies have showed that CPR knowledge and skills deteriorate three to six months after the initial training implying the need for repeat training (Bhanji et al., 2015).

A study that assessed the BLS knowledge of students in a rural location in the UK, using a 22-items' questionnaire, found a significant increase knowledge following training. Although knowledge retention decreased over a six-months' period, it remained significantly higher than that of a comparable group of students who had never received training. The authors concluded that this type of training, if included in the curriculum, could have a positive impact on public health. (Connolly et al., 2007).

In a recent study, five students at different secondary schools in London died of sudden cardiac arrest within a period of ten years (Salciccioli et al., 2017).This reinforces the need for basic life support training for students, which in the longterm will contribute a larger general population with knowledge and skills in CPR.

BLS training for lay people using chest compressions only, as advocated by the American Heart Association, can fill this knowledge gap and assist in maintaining life until the arrival of specialized help. In this study, we chose to teach the full basic life support course, due to the range of students/courses involved in the training.

This standard for training lay persons has been used in other countries, but in a simplified manner. For instance, in the cross-sectional telephone study involving 404 adults living in the Australian state of Victoria where $67 \%$ of respondents reported being instructed to use only their hands to care for unknown victims (Bray et al., 2017).

It was observed that the pre-training skills' scores were very low, showing inadequate skill to effectively perform the BLS technique. This however, increased significantly after the training. A study conducted in India with 42 first-year medical students corroborates these data. The students were assessed on their knowledge and skills before and after a lecture provided in conjunction with demonstrations using BLS care simulators. In this study, after practical training, $74 \%$ of the students performed the steps correctly, showing that the training program provided students with effective BLS knowledge and skills (Pande et al., 2014).

In another study conducted in China, in which pre-training assessment and immediate feedback after the training were provided as evidence knowledge and skills acquisition by medical students in the execution of BLS, the knowledge and skills gained was higher in the experimental group that received 30 minutes of practical training in Basic Life Support compared to the control group that $\operatorname{did} \operatorname{not}(\mathrm{p}<0.001)$ (Li et al., 2013).

To address the second objective of this study, multiple linear regression analysis was used to describe relationships between pre- and post-training scores and some explanatory variables. Before the training, a statistically significant positive association was observed between knowledge and age, knowledge and background training. After the training, this relationship was only observed with age. Based on these data, we ought to consider the influence of life years gained on knowledge acquisition.

In a different study, the effects of age, time since graduation from nursing or medical school, sex, medical specialty, and workplace on knowledge retention in Advanced Cardiac Life Support (ACLS) Courses was assessed. This study 
conducted on 425 participants, showed that advanced age and the longest period since graduation were directly related to the worst test scores and the lowest levels of knowledge retention (Miotto et al., 2008).

In this study age had a direct significant association with psychomotor skills acquisition with each year increase in age, the test score increased by 8.21 points after training. This data led us to consider the beneficial effect of participants' age in performing CPR procedures.

In a recent study carried out on 501 participants who answered a telephone-administered questionnaire, the level of knowledge and a decreasing desire for BLS attempts was observed with increasing age (Krammel et al., 2018).

In another investigation that aimed to determine the optimal age ranges for implementing basic life support and chest compression course in Thai adolescents showed that after theory lecture and hand-on training, the age groups of 13 to 14, 15 to 16 , and 17 to 18 -year-olds could perform quality chest compression with similar success rates. The authors concluded that Basic life support and chest compression course could therefore be commenced at the age of thirteen (Kaweenuttayanon et al., 2017).

It is possible that the use of a problem situation in our study may have contributed to participants' motivation and positively influenced test results. Another relevant fact of this study was that students who obtained high knowledge scores before the training also maintained high knowledge scores after the training. The knowledge gained however, was higher among students who had no prior training or information.

The study contributed to knowledge acquisition as it trained people, mostly laypersons, to provide assistance in various emergency situations using standardized procedures and techniques, which are not always addressed by undergraduate courses offered in the country.

Universities are an ideal setting for this type of training because they are highly-populated with people at risk of getting into all types of emergency situations, such as cardiac arrests. Ideally, this content should be offered as an obligatory discipline in the first year undergraduate curriculum. Alternatively, this training could be offered at the national level to lay persons, however, this depends on government initiatives and such initiative are not usually prioritized in developing countries.

One main limitation of this study was that it was cross-sectional and therefore it is not possible to compare results of assessments done at different times.

\section{Conclusion}

The study results indicate that training contributes to improved knowledge about the appropriate care in emergency situations and enhanced skills in basic life support techniques. Age was the only variable that independently influenced learning and psychomotor skills following the training.

The development of different teaching and learning skills converges to a critical and transforming pedagogical action in which the use of active methodologies can change the current paradigms, and transform teaching environments into meaningful experiences so that a student can advance in his/her own knowledge.

The success of meaningful learning requires breaking the existing dichotomy between theory and practice and promoting the articulation of content with action, considering the student as responsible for their learning.

\section{References}

Atwood, C., Eisenberg, M. S., Herlitz, J., \& Rea, T. D. (2005). Incidence of EMS-treated out-of-hospital cardiac arrest in Europe. Resuscitation, 67(1), 75-80. https://doi.org/10.1016/j.resuscitation.2005.03.021

Ausubel, D. P., Novak, J. D., \& Hanesian, H. (1991). Psicología educativa: Un punto de vista cognoscitivo. Trillas.

Bakke, H. K., Steinvik, T., Angell, J., \& Wisborg, T. (2016). A nationwide survey of first aid training and encounters in Norway. BMC Emergency Medicine, 17(1), 6. https://doi.org/10.1186/s12873-017-0116-7

Berdowski, J., Berg, R. A., Tijssen, J. G. P., \& Koster, R. W. (2010). Global incidences of out-of-hospital cardiac arrest and survival rates: Systematic review of 67 prospective studies. Resuscitation, 81(11), 1479-1487. https://doi.org/10.1016/j.resuscitation.2010.08.006

Berg, R. A., Hemphill, R., Abella, B. S., Aufderheide, T. P., Cave, D. M., Hazinski, M. F., .. Swor, R. A. (2010). Part 5: Adult Basic Life Support: 2010 American Heart Association Guidelines for Cardiopulmonary Resuscitation and Emergency Cardiovascular Care. Circulation, 122(18_suppl_3), S685-S705. https://doi.org/10.1161/CIRCULATIONAHA.110.970939

Bhanji, F., Donoghue, A. J., Wolff, M. S., Flores, G. E., Halamek, L. P., Berman, J. M., ... Cheng, A. (2015). Part 14: Education: 2015 American Heart Association Guidelines Update for Cardiopulmonary Resuscitation and Emergency Cardiovascular Care. Circulation, 132(18 supp12), S561-S573. Chang A. (2015). Part 14: education. American Heart Association guidelines update for cardiopulmonary resuscitation and emergency cardiovascular care. Circulation, 


\section{3;132(18 Suppl 2): S561-73 (2015). https://doi.org/10.1161/CIR.0000000000000268}

Biblioteca Virtual da Saúde. Descritores em Ciências da Saúde (DECS). http://decs.bvs.br/

Bray, J. E., Smith, K., Case, R., Cartledge, S., Straney, L., \& Finn, J. (2017). Public cardiopulmonary resuscitation training rates and awareness of hands-only cardiopulmonary resuscitation: A cross-sectional survey of Victorians: CPR Training and awareness of hands-only CPR. Emergency Medicine Australasia, 29(2), 158-164. https://doi.org/10.1111/1742-6723.12720

Connolly, M., Toner, P., Connolly, D., \& McCluskey, D. R. (2007). The 'ABC for life' programme-Teaching basic life support in schools. Resuscitation, 72(2), 270-279. https://doi.org/10.1016/j.resuscitation.2006.06.031

De Buck, E., Van Remoortel, H., Dieltjens, T., Verstraeten, H., Clarysse, M., Moens, O., \& Vandekerckhove, P. (2015). Evidence-based educational pathway for the integration of first aid training in school curricula. Resuscitation, 94, 822. https://doi.org/10.1016/j.resuscitation.2015.06.008

Dixe, M. dos A. C. R., \& Gomes, J. C. R. (2015). Knowledge of the Portuguese population on Basic Life Support and availability to attend training. Revista da Escola de Enfermagem da USP, 49(4), 0640-0649. https://doi.org/10.1590/S0080-623420150000400015

Gebreegziabher Gebremedhn, E., BerheGebregergs, G., Anderson, B. B., \& Nagaratnam, V. (2017). Attitude and skill levels of graduate health professionals in performing cardiopulmonary resuscitation. Advances in Medical Education and Practice, Volume 8, 43-50. https://doi.org/10.2147/AMEP.S114726

Go, A. S., Mozaffarian, D., Roger, V. L., Benjamin, E. J., Berry, J. D., Blaha, M. J., ... Turner, M. B. (2014). Heart Disease and Stroke Statistics-2014 Update: A Report From the American Heart Association. Circulation, 129(3). https://doi.org/10.1161/01.cir.0000441139.02102.80

Gonzalez, M. M., Timerman, S., Oliveira, R. G. de, Polastri, T. F., Dallan, L. A. P., Araújo, S., ... Favarato, M. H. (2013). I Guideline for Cardiopulmonary Resuscitation and Emergency Cardiovascular Care - Brazilian Society of Cardiology: Executive Summary. Arquivos Brasileiros de Cardiologia, 100(2), 105-113. https://doi.org/10.5935/abc.20130022

Kaweenuttayanon, N., Phungoen, P., Kotruchin, P., Ianghong, K., Chantawattanaruk, S., \& Pongchaiyakul, C. (2017). Defining the Optimal Age for Basic Life Support and Cardiac Compression Training in Thai Adolescents. Defining the Optimal Age for Basic Life Support and Cardiac Compression Training in Thai Adolescents., 100(9), 967-971.

Kleinman, M. E., Brennan, E. E., Goldberger, Z. D., Swor, R. A., Terry, M., Bobrow, B. J., ... Rea, T. (2015). Part 5: Adult Basic Life Support and Cardiopulmonary Resuscitation Quality: 2015 American Heart Association Guidelines Update for Cardiopulmonary Resuscitation and Emergency Cardiovascular Care. Circulation, 132(18 suppl 2), S414-S435. https://doi.org/10.1161/CIR.0000000000000259

Ko, S. Y., Ro, Y. S., Shin, S. D., Song, K. J., Hong, K. J., \& Kong, S. Y. (2018). Effect of a first responder on survival outcomes after out-of-hospital cardiac arrest occurs during a period of exercise in a public place. PLOS ONE, 13(2), e0193361. https://doi.org/10.1371/journal.pone.0193361

Krammel, M., Schnaubelt, S., Weidenauer, D., Winnisch, M., Steininger, M., Eichelter, J., ... Sulzgruber, P. (2018). Gender and age-specific aspects of awareness and knowledge in basic life support. PLOS ONE, 13(6), e0198918. https://doi.org/10.1371/journal.pone.0198918

Leary, M., David, G. B., Daniel, J. I., Daiane, A. S., Robert, A. B., Vinay, M. N., .. Benjamin, S. A. (2017). The association of layperson characteristics with the quality of simulated cardiopulmonary resuscitation performance. World Journal of Emergency Medicine, 8(1), 12. https://doi.org/10.5847/wjem.j.1920-8642.2017.01.002

Li, Q., Zhou, R., Liu, J., Lin, J., Ma, E. L., Liang, P., ... Xiao, H. (2013). Pre-training evaluation and feedback improved skills retention of basic life support in medical students. Resuscitation, 84(9), 1274-1278. https://doi.org/10.1016/j.resuscitation.2013.04.017

Mawani, M., Kadir, M. M., Azam, I., Mehmood, A., McNally, B., Stevens, K., ... Razzak, J. A. (2016). Epidemiology and outcomes of out-of-hospital cardiac arrest in a developing country-a multicenter cohort study. BMC Emergency Medicine, 16(1), 28. https://doi.org/10.1186/s12873-016-0093-2

Medical Subject Headings (MESH). National Center for Biotechnology Information (NCBI). https://www.ncbi.nlm.nih.gov/mesh

Mendoza, I. Y. Q., \& Peniche, A. de C. G. (2012). Intervenção educativa sobre hipotermia: Uma estratégia de ensino para aprendizagem em centro cirúrgico. Revista da Escola de Enfermagem da USP, 46(4), 851-857. https://doi.org/10.1590/S0080-62342012000400010

Miotto, H. C., Couto, B. R. G. M., Goulart, E. M. A., Amaral, C. F. S., \& Moreira, M. da C. V. (2008). Advanced Cardiac 
Life Support Courses: Live actors do not improve training results compared with conventional manikins. Resuscitation, 76(2), 244-248. https://doi.org/10.1016/j.resuscitation.2007.07.031

Moreira, M. A. (2012). La teoría de la prendizaje significativo crítico: Un referente para organizar la enseñanza contemporánea. Revista iberoamericana de educación matemática, 31, 9-20.

Moreira, M. A. (2014). Enseñanza de la fisica: Aprendizaje significativo, aprendizaje mecánico y criticidad, 26(1), 4552.

Pande, S., Pande, S., Parate, V., Pande, S., \& Sukhsohale, N. (2014). Evaluation of retention of knowledge and skills imparted to first-year medical students through basic life support training. Advances in Physiology Education, 38(1), 42-45. https://doi.org/10.1152/advan.00102.2013

Pelizzari, A., Kriegl, M. D. L., Baron, M. P., Finck, N. T. L., \& Dorocinski, S. I. (2002). Teoria da aprendizagem significativa segundo Ausubel. Teoria da aprendizagem significativa segundo Ausubel, 2(1), 37-42.

Prado, C., Vaz, D. R., \& Almeida, D. M. de. (2011). Teoria da aprendizagem significativa: Elaboração e avaliação de aula virtual na plataforma Moodle. Revista Brasileira de Enfermagem, 64(6), 114-1121. https://doi.org/10.1590/S003471672011000600019

Ro, Y. S., Shin, S. D., Song, K. J., Lee, E. J., Kim, J. Y., Ahn, K. O., ... Hwang, S. S. (2013). A trend in epidemiology and outcomes of out-of-hospital cardiac arrest by urbanization level: A nationwide observational study from 2006 to 2010 in South Korea. Resuscitation, 84(5), 547-557. https://doi.org/10.1016/j.resuscitation.2012.12.020

Salciccioli, J. D., Marshall, D. C., Sykes, M., Wood, A. D., Joppa, S. A., Sinha, M., \& Lim, P. B. (2017). Basic life support education in secondary schools: A cross-sectional survey in London, UK. BMJ Open, 7(1), e011436. https://doi.org/10.1136/bmjopen-2016-011436

Shenzhen, China, Fan, K., Leung, L., \& Siu, Y. (2017a). Out-of-hospital cardiac arrest in Hong Kong: A territory-wide study. Hong Kong Medical Journal. https://doi.org/10.12809/hkmj166046

Sladjana, A. (2011). A prediction survival model for out-of-hospital cardiopulmonary resuscitations. Journal of Critical Care, 26(2), 223.e11-223.e18. https://doi.org/10.1016/j.jcrc.2010.06.001

Smereka, J., Aluchna, M., Aluchna, A., \& Szarpak, Ł. (2019). Preparedness and attitudes towards medical emergencies in the dental office among Polish dentists. International Dental Journal, 69(4), 321-328. https://doi.org/10.1111/idj.12473

Sobral, F. R., \& Campos, C. J. G. (2012). Utilização de metodologia ativa no ensino e assistência de enfermagem na produção nacional: Revisão integrativa. Revista da Escola de Enfermagem da USP, 46(1), 208-218. https://doi.org/10.1590/S0080-62342012000100028

Sousa, A. T. O. de, Formiga, N. S., Oliveira, S. H. dos S., Costa, M. M. L., \& Soares, M. J. G. O. (2015). A utilização da teoria da aprendizagem significativa no ensino da Enfermagem. Revista Brasileira de Enfermagem, 68(4), 713-722. https://doi.org/10.1590/0034-7167.2015680420i

Stiell, I., Nichol, G., Wells, G., De Maio, V., Nesbitt, L., Blackburn, J., \& Spaite, D. (2003). Health-Related Quality of Life Is Better for Cardiac Arrest Survivors Who Received Citizen Cardiopulmonary Resuscitation. Circulation, 108(16), 1939-1944. https://doi.org/10.1161/01.CIR.0000095028.95929.B0

Tannvik, T. D., Bakke, H. K., \& Wisborg, T. (2012). A systematic literature review on first aid provided by laypeople to trauma victims: Lay first responders in trauma. Acta Anaesthesiologica Scandinavica, 56(10), 1222-1227. https://doi.org/10.1111/j.1399-6576.2012.02739.x

Van de Velde, S., Broos, P., Van Bouwelen, M., De Win, R., Sermon, A., Verduyckt, J., ... Aertgeerts, B. (2007). European first aid guidelines. Resuscitation, 72(2), 240-251. https://doi.org/10.1016/j.resuscitation.2006.10.023

Viereck, S., Møller, T. P., Rothman, J. P., Folke, F., \& Lippert, F. K. (2017). Recognition of out-of-hospital cardiac arrest during emergency calls-A systematic review of observational studies. Scandinavian Journal of Trauma, Resuscitation and Emergency Medicine, 25(1), 9. https://doi.org/10.1186/s13049-017-0350-8

\section{Copyrights}

Copyright for this article is retained by the author(s), with first publication rights granted to the journal.

This is an open-access article distributed under the terms and conditions of the Creative Commons Attribution license which permits unrestricted use, distribution, and reproduction in any medium, provided the original work is properly cited. 